\title{
A Study of Role of FNAC in Palpable Breast Lump
}

\author{
Aparna Vyas ${ }^{1}$, Naresh N Rai ${ }^{2}$
}

\begin{abstract}
Aims and Objectives: Breast carcinoma is the most common malignant tumor worldwide in women while it is the second most common cancer in India. Triple assessment, including clinical assessment, radiological imaging and pathological diagnosis is the most widely accepted protocol followed for diagnosis of breast lump. Fine-needle aspiration cytology (FNAC) is the most important part of triple assessment. The purpose of our study was to establish the role of FNAC in the diagnosis of breast lump, to study the various types of breast lumps, and to observe any correlation of fine needle cytology with postoperative histopathology.

Materials and methods: The study group included 128 consecutive female patients presenting with palpable breast lump during a one year period. FNAC of patients was performed with non-aspiration technique. Smears prepared and stained with Giemsa stain and examined for cytological diagnosis. Routine histopathological examination was performed on available surgical biopsy specimens to correlate cytological and histopathological diagnosis.

Results: A total of 128 cases were included out of which 126 cases had adequate sample and 2 cases were categorised as unsatisfactory. Out of 126 adequate samples 102 were benign, 21 were malignant and 3 cases were of atypical ductal hyperplasia. Fibroadenoma accounted for maximum number of cases, and infiltrating duct carcinoma was most common malignant lesion in our study. Histopathological correlation was obtained in 95 cases out of 126 cases and among these $80 \%$ were benign and remaining $20 \%$ were malignant. Out of 76 benign lesions on cytology, 75 were confirmed as benign but one case was reported as malignant on histopathological examination. All the cytologically diagnosed malignant cases were confirmed as malignant on subsequent histopathological examinations

Conclusion: The most common benign tumor in the present study was fibroadenoma and the most common malignant tumor was infiltrating duct carcinoma.. Our study showed $0 \%$ false positivity and the false negative rate was $5.26 \% .27$ Our study showed a sensitivity of $94.74 \%$ a very high specificity of $100 \%$.

Keywords: Breast carcinoma, Breast lump, Preoperative diagnosis

Journal of Mahatma Gandhi University of Medical Sciences and Technology (2018): 10.5005/jp-journals-10057-0067
\end{abstract}

\section{INTRODUCTION}

Breast carcinoma is the most common malignant tumor worldwide in women ${ }^{1}$ while it is the second most common cancer in India. ${ }^{2}$ There are approximately, 75,000 new cases of breast cancer detected in India yearly. ${ }^{3}$ Breast neoplasm constitutes the most important lesions of breast and includes neoplasm arising from ductal, glandular structures and mesenchymal connective tissues. $^{4}$

With growing awareness in the general population, especially about breast related problems, a lady with a breast lump is one of the common complaints in patients attending OPD. To rule out malignancy, every woman presenting with a breast mass should be evaluated to exclude or establish a diagnosis of cancer. ${ }^{5}$ For diagnosing breast lesions, presently radiological imaging in combination with needle biopsy has many advantages such as, it offers preoperative diagnosis, relieves patient's anxiety, saves time, and definitive treatment can be planned in advance etc. ${ }^{6}$

"Triple assessment", including clinical assessment, radiological imaging and pathological diagnosis is the most widely accepted protocol followed for diagnosis of breast lump. FNAC is the most important part of triple assessment. One of the major goals of FNA from breast is to differentiate benign from malignant lesions. ${ }^{7}$

The purpose of our study was to establish the role of FNAC in the diagnosis of breast lump. In our study an attempt has been made to study the various types and presentations of breast lumps, and to observe any correlation of Fine Needle Cytology with postoperative Histopathology, various pathological types and their relative percentages.
${ }^{1}$ Chief Medical Officer, ${ }^{2}$ Senior Professor

${ }^{1}$ Department of Pathology, ESIC Model Hospital, Jaipur, Rajasthan, India

${ }^{2}$ Department of Pathology, Government Medical College, Kota, Rajasthan, India

Corresponding Author: Aparna Vyas, Chief Medical Officer, Department of Pathology, ESIC Model Hospital, Jaipur, Rajasthan, India, Phone: 8003405648, e-mail: draparnavyas@gmail.com

How to cite this article: Vyas A, Rai NN. A Study of Role of FNAC in Palpable Breast Lump. J Mahatma Gandhi Univ Med Sci Tech 2018;3(1):1-6.

Source of support: Nil

Conflict of interest: None

\section{Materials and Methods}

The present study is a prospective study conducted in Department of Pathology of tertiary care hospital attached to a medical college. The study group included 128 consecutive female patients presenting with palpable breast lump in department of pathology during a 1 year period. Patient's socio-demographic details and clinical data regarding the site of involvement, size of the lesion, laterality of lump, duration etc. were recorded.

FNAC of patients was performed after taking informed written consent with non-aspiration technique. Smears prepared and stained with Giemsa stain and examined under light microscope and cytological diagnosis was made. Routine histopathological examination was performed on available surgical biopsy specimens to correlate cytological and histopathological diagnosis.

() The Author(s). 2018Open Access This article is distributed under the terms of the Creative Commons Attribution 4.0 International License (https://creativecommons. org/licenses/by-nc/4.0/), which permits unrestricted use, distribution, and non-commercial reproduction in any medium, provided you give appropriate credit to the original author(s) and the source, provide a link to the Creative Commons license, and indicate if changes were made. The Creative Commons Public Domain Dedication waiver (http://creativecommons.org/publicdomain/zero/1.0/) applies to the data made available in this article, unless otherwise stated. 


\section{Results}

In the present study a total of 128 cases were included out of which 126 cases had adequate sample and 2 cases were categorised as unsatisfactory. The histopathological correlation could be obtained in 95 cases. Out of 126 adequate samples 102 (80.95\%) were benign, $21(16.66 \%)$ were malignant and $3(2.38 \%)$ case were of atypical ductal hyperplasia (Table 1).

Patients age range was 13-80 years with an average age of 46.5 years. Most common age group affected by benign lesion was 11-20 years followed by 21-30, 31-40 and 41-50 years. Malignant lesion were common in 41-50 (33.36\%) and 31-40 (28.53\%) years. (Table 2). Right breast was involved in majority of cases. Upper outer quadrant was commonly affected but the benign lesions were common in upper inner quadrant (33.66\%) followed by upper outer quadrant $(29.7 \%)$ and malignant lesions were common in upper outer quadrant (Figs 1 and 2). Fibroadenoma (56.86\%) was the commonest benign lesion encountered in the present study (Fig. 3) while duct carcinoma (90.47\%) was the most common malignant lesion (Fig. 4).

In our study histopathological correlation was obtained in 95 cases out of 126 cases and among these $80 \%$ were benign

Table 1: Distribution of total cases on cytological examination

\begin{tabular}{lll}
\hline Category & Number of cases & Percentage (\%) \\
\hline Benign & 102 & 80.95 \\
Malignant & 21 & 16.66 \\
Atypical ductal hyperplasia & 3 & 2.38 \\
Total & 126 & 100 \\
\hline
\end{tabular}

Table 2: Distribution of the cases studied according to age

\begin{tabular}{lllll}
\hline $\begin{array}{l}\text { Age group } \\
\text { (years) }\end{array}$ & $\begin{array}{l}\text { Total cases } \\
(\%)\end{array}$ & $\begin{array}{l}\text { Atypical ductal } \\
\text { Benign (\%) }\end{array}$ & $\begin{array}{l}\text { Malignant } \\
\text { hyperplasia (\%) }\end{array}$ \\
\hline$\leq 20$ & $40(31.7)$ & $39(38.23)$ & 0 & $1(4.76)$ \\
$21-30$ & $37(29.3)$ & $36(35.29)$ & 0 & $1(4.76)$ \\
$31-40$ & $25(19.8)$ & $19(18.62)$ & 0 & $6(28.53)$ \\
$41-50$ & $16(12.6)$ & $7(6.86)$ & $2(66.66)$ & $7(33.3)$ \\
$51-60$ & $2(1.58)$ & 0 & $1(33.33)$ & $1(4.76)$ \\
$61-70$ & $4(3.17)$ & $1(.98)$ & 0 & $3(14.2)$ \\
$71-80$ & $2(1.58)$ & 0 & 0 & $2(9.5)$ \\
Total & 126 & $102(80.95)$ & $3(2.38)$ & $21(16.66)$ \\
\hline
\end{tabular}

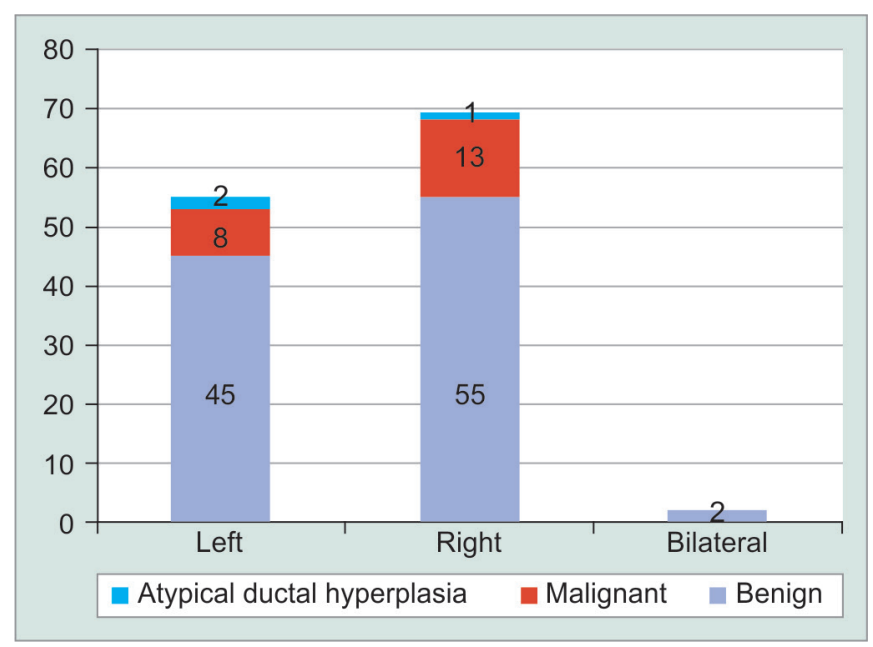

Fig. 1: Distribution of cases according to side of breast involvement

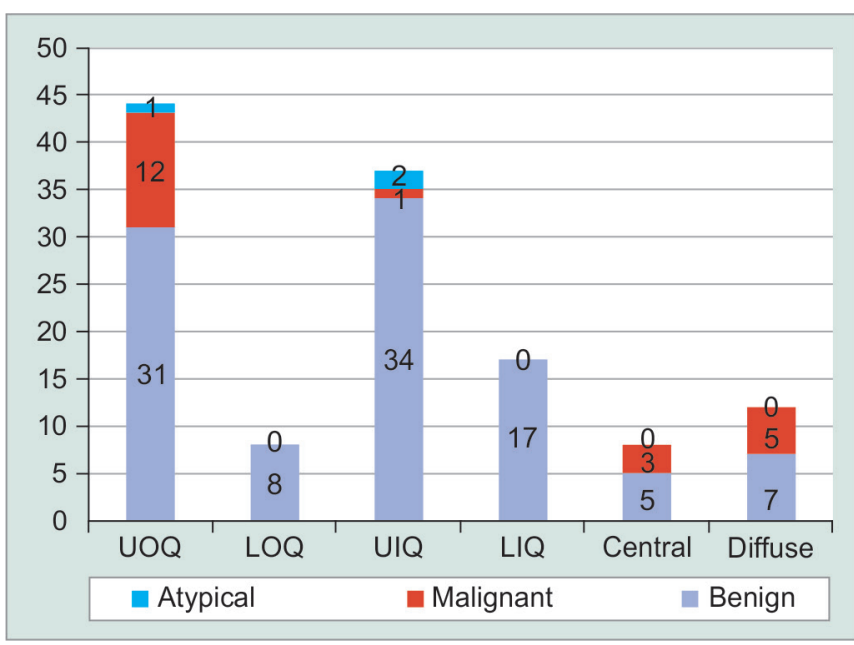

Fig. 2: Distribution of cases according to side (Quadrant) of breast involvement

$\mathrm{UOQ}=$ Upper outer quadrant; $\mathrm{LOQ}=$ Lower outer quadrant

$\mathrm{UIQ}=$ Upper inner quadrant; LIQ = Lower inner quadrant

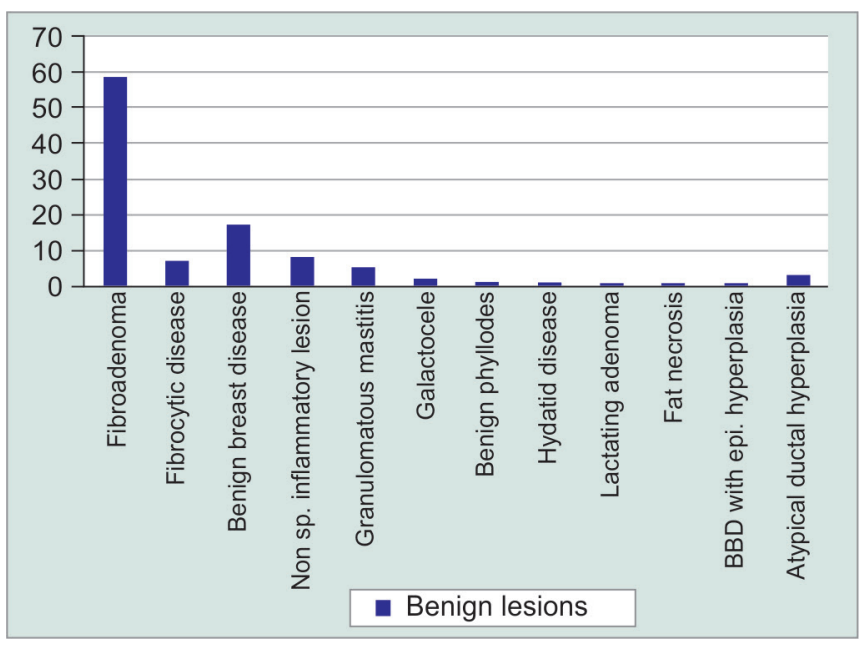

Fig. 3: Percentage distribution of different type of benign breast lump on cytology

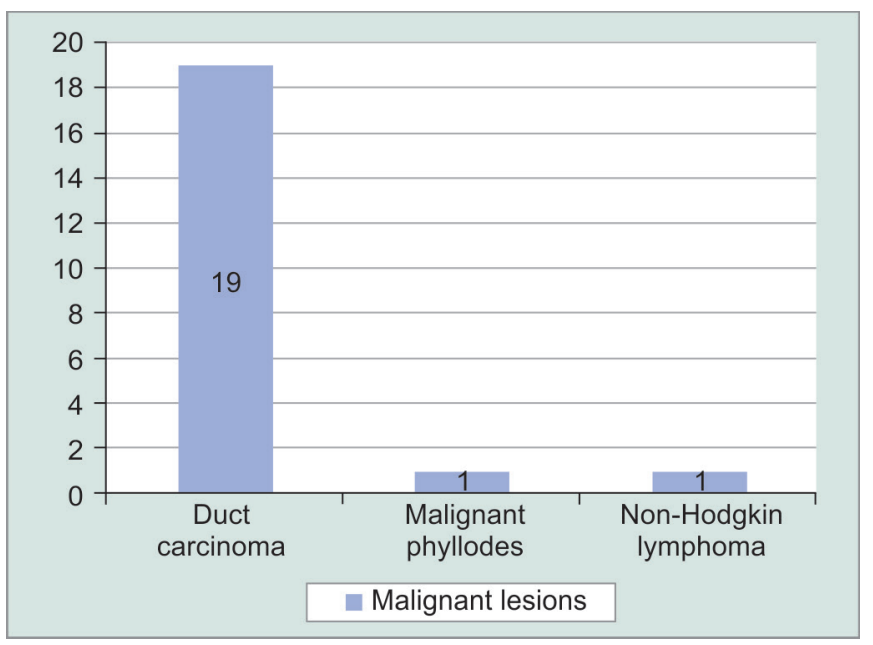

Fig. 4: Percentage distribution of different type of malignant breast lump on cytology 
and remaining 20\% were malignant. Out of 76 benign lesions on cytology, 75 were confirmed as benign but one case was reported as malignant on histopathological examination. All 18 cytologically malignant lesions were confirmed to be malignant on histopathological examination. One case reported as papillary neoplasm, atypical ductal hyperplasia on cytology was reported as fibrocystic disease with usual ductal hyperplasia on histopathology (Table 3).

Cyto-histopathological correlation of 56 cases diagnosed as fibroadenoma on cytology showed that 53 cases of these were confirmed as fibroadenoma on histopathology whereas one each as fibrocystic disease, fibroadenosis and tubular adenoma respectively. Under category of benign breast disease comprising of 17 cases (16.83\%), histopathological correlation was obtained in 9 of these cases with 3 cases confirmed to be of fibrocystic disease, 3 of fibroadenosis, 2 of fibroadenoma and 1 of fibroadenomatosis. We reported a lesion as benign phyllodes on cytological examination in a 20 year old female, same was reported as juvenile fibroadenoma on histopathological examination. A very interesting case of hydatid disease of breast was reported in a 50 year old female on cytology during our study period and was confirmed on histopathological examination (Fig. 5).

The cyto-histopathological correlation with malignant lesions revealed that among 16 cytologically reported duct carcinoma cases, 13 were confirmed as infiltrating duct carcinoma while one each was reported as infiltrating lobular carcinoma, glycogen rich clear cell carcinoma and as Infiltrating duct carcinoma mixed with lobular carcinoma on histopathology. Single case of malignant phyllodes on cytology was reported as mesenchymal sarcoma on histopathological examination. One case of Non-Hodgkins lymphoma on cytology was classified as diffuse Large B-cell lymphoma, Burkitt type on histopathological examination. The statistical analysis of our study showed sensitivity of FNAC to be $94.74 \%$, specificity to be $100 \%$, and positive and negative predictive value to be $100 \%$ and $98.68 \%$ respectively. The overall diagnostic activity was derived as $98.93 \%$.

\section{Discussion}

In our study, maximum number of cases (30.95\%) were found in the $\leq 20$ year age group, closely followed by 21 to 30 year age group (30.15\%) which is similar to study done by Sadik et al. ${ }^{8}$ Benign lesions were found in all age group with majority of them between 10 to 40 years. In contrast majority of malignant lesions were found between 31 to 50 years. This distribution is similar to several other studies done by other authors. ${ }^{3,8-11}$

Our study showed involvement of right breast slightly higher than left breast. Other studies ${ }^{1,3}$ found almost equal involvement of right and left breast in different types of cytological lesions. According to WHO classification of breast tumors, ${ }^{12}$ invasive breast carcinoma has a slightly higher incidence in left breast with left to right ratio of 1.07 to 1 . However this observation holds no surgical importance either in the form of patient selection or mode of treatment. The upper outer quadrant was the most common site of involvement in our study which was in concordance with other studies. 3,9

Several authors reported fibroadenoma as the most common diagnosis ranging from 46 to $72.8 \%$ in their studies. ${ }^{13-15}$ The cytological spectrum of various benign breast lesions encountered in our study also revealed that fibroadenoma accounted for maximum cases that is 58 cases (57.4\%). However majority of fibroadenoma cases in our study were in 10 to 20 year age group which is similar to the study of Sadik et al. ${ }^{8}$ but different from others, like the study of Rahman et al. ${ }^{1}$ who found majority of cases in 21 to 30 year age group.

One case reported as benign breast disease on cytology was reported to be of Infiltrating duct carcinoma with areas of necrosis in histopathology of lumpectomy specimen. This single case represents the only false negative of this present study. This false negative case showed cytological smears of mild to moderate cellularity, benign tight clusters with mild atypia and few single bare nuclei. Clinically it was large lump and it is possible that small area of malignancy was present in a large fibrocystic area.

In present study, third most common diagnosis was of non-specific inflammatory lesion consisting of 8 cases $(7.8 \%)$ and fibrocystic disease comprising 7 cases (6.8\%) respectively. Histopathological confirmation was obtained in only 2 of these inflammatory cases as the rest did not undergo biopsy. In our study we found patients with fibrocystic disease distributed almost equally in 2 nd, 3rd and 4th decade, various similar studies ${ }^{16,17}$ also reported it to be most common in 3rd and 4th decade.

According to Hanif et al. ${ }^{18}$ the overall incidence of granulomatous mastitis is less than $0.1 \%$ of all breast lesions in developed countries and $3-4 \%$ in developing countries. Some infectious etiology, foreign material like breast prosthesis or systemic disease may involve breast resulting in granulomatous mastitis. ${ }^{19}$ Our study had 5 cases $(4.9 \%)$ of granulomatous mastitis but histopathological correlation was obtained in only 1 of them which proved to be a case of fibrocystic disease in association with granulomatous mastitis.

We reported a lesion as benign phyllodes on cytological examination in a 20 year old female; same was reported as juvenile fibroadenoma on histopathological examination. This was probably due to the greater cellular stroma and presence of mitoses in juvenile fibroadenoma.

A case of hydatid disease of breast reported in a 50 year old female presenting as a breast abscess was also included in our study and it was confirmed on histopathological examination. Therefore any acute inflammatory mass particularly any cystic lesion should be thoroughly examined keeping in mind the differential diagnosis of hydatid disease particularly in India, especially if associated with a watery colour aspirate (Fig. 1).

Malignant breast lesions were found in all age groups with youngest being 20 and oldest 80 year old. Malignancy was most common in 31 to 50 year age group comprising of 12 cases (57.1\%), and infiltrating duct carcinoma was most common malignant lesion in our study. This finding is in accordance with study of Rahman et al. ${ }^{1}$ who also concluded that majority of malignant lesions were found in middle age group of 31 to 50 years. Similar results from other studies in India like Muddegowda et al. ${ }^{20}$ and Khemka et al ${ }^{9}$ were reported. However reports from western world depict 5 th and 6th decade as predominant age group for breast cancer. ${ }^{21}$

All the cytologically diagnosed malignant cases were confirmed as malignant on subsequent histopathological examinations, but there were discrepancies in sub-categorization of malignant lesions. One such case of duct carcinoma on cytology proved to be infiltrating lobular carcinoma on histopathological examination and other as mixed infiltrating duct-lobular carcinoma. Similarly another such case was reported as glycogen rich clear cell carcinoma on histopathological examination. Malignant phyllodes were reported as mesenchymal sarcoma on histopathology. There was also one case of non-Hodgkin lymphoma reported as diffuse large B-cell lymphoma possibly Burkitt type. 


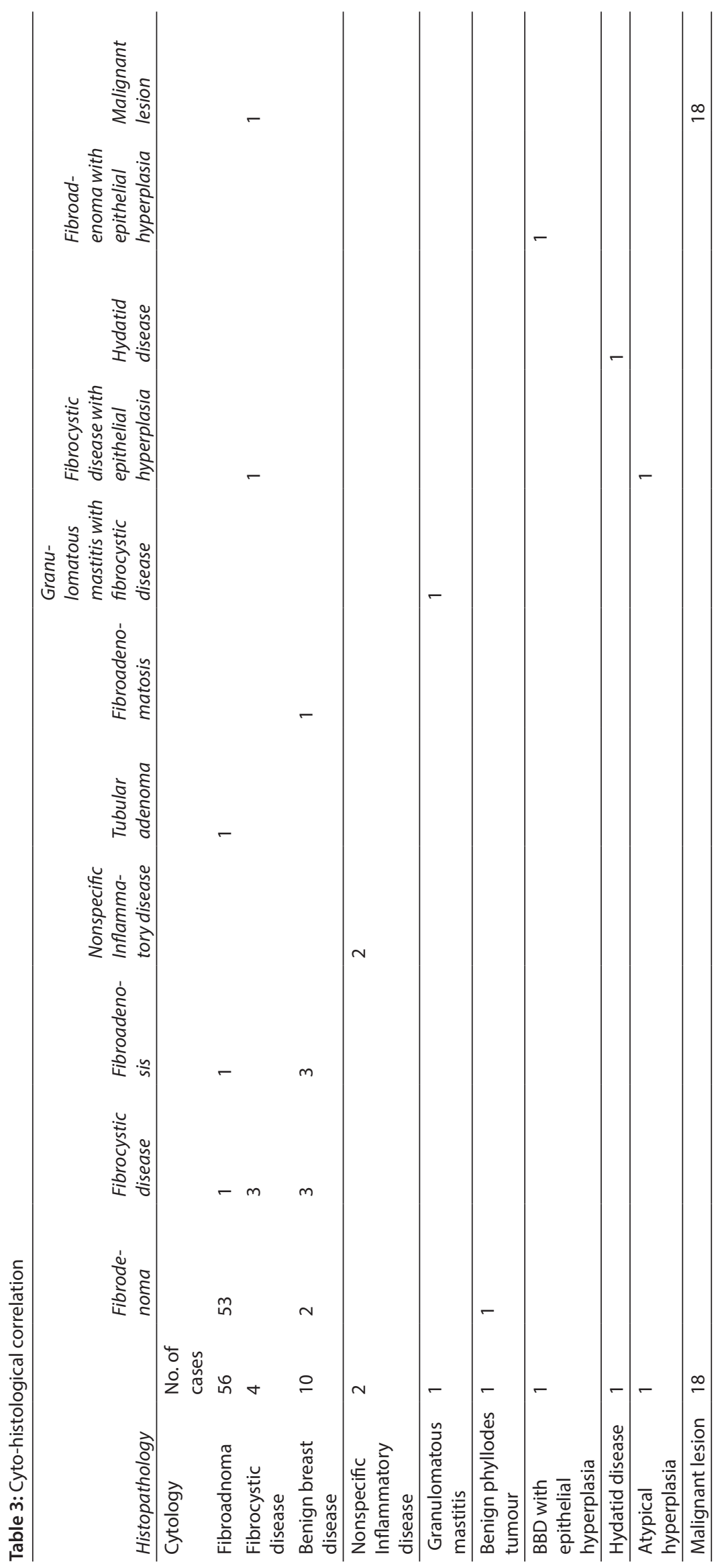



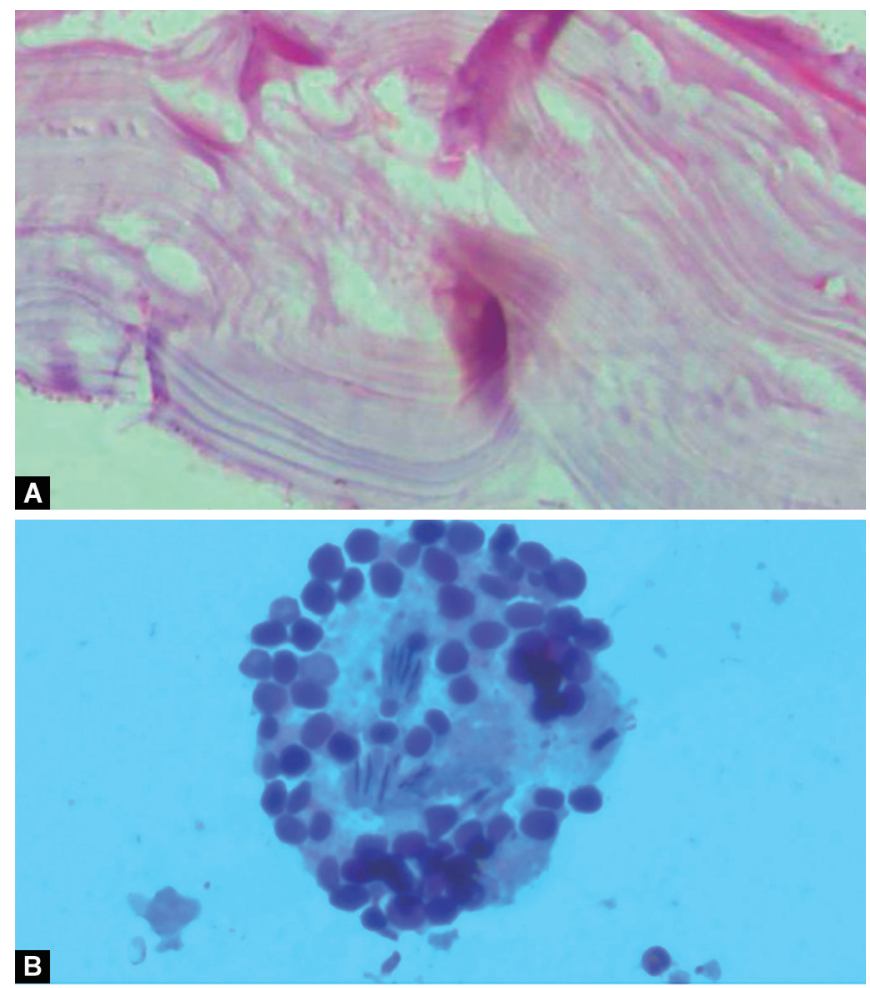

Figs 5A and B: Microphotograph. Hydatid disease of breast (A) (100X showing hooklets. (Giemsa stain); (B) (200X, H and E) showing laminated membrane

Observations show that though FNAC may be very useful for broad categorisation of benign and malignant lesions, but in our study it didn't prove to be good enough for sub-categorisation of same.

In our present study the false negative rate was $5.26 \%$. This was due to a single case of infiltrating duct carcinoma which was categorised as benign breast disease on cytology. On histopathological examination this case revealed large benign areas and central necrosis. There is a risk of false negative results in low grade malignancies, small or complex proliferative lesions as well as in tumours with central necrosis or a small cell carcinoma. ${ }^{9}$ In the literature the false negative rate shows a range from 0 to $35 \%$. In one large series by Feichter et al. ${ }^{22}$ (1997) they observed $9 \%$ false negativity.

It is worth mentioning that though false negative rate pose a major concern in screening of breast lumps, it is also true they are more common in some settings than others. This is thus largely attributed to sampling errors. This again lays emphasis on Triple Assessment of breast lumps and a highly suspicious lesion on clinical and mammographic examination should be subjected to repeat FNAC or surgical biopsy. Also some forms of cancers are more likely to be poorly sampled or missed by FNAC.

Several studies have shown a very low false positive rate. Muddegowda et al. ${ }^{20}$ reported it to be $1.3 \%$. Our study showed $0 \%$ false positivity. Patel et al. ${ }^{23}$ (1987) concluded that false positive diagnosis are a reflection of limited experience and not a limitation of the cytological technique. A positive diagnosis should be made only when there was incontrovertible evidence of malignancy. In present study the false positive and false negative rates are within the preferred rates as per the recommendations by UK NHS BSP June 2001. ${ }^{24}$
Review of several studies by various authors have reported a high sensitivity rate ranging from 88.3 to $99 \% .^{3,9,10,20,25-27}$ Our study also showed result in accordance with these studies with a sensitivity of $94.74 \%$. Similarly many authors reported a very high specificity between 94 to $100 \% .^{3,9,10,20,25,27-31}$ Result of our study also showed a very high specificity of $100 \%$. In our study we calculated a positive and negative predictive value of $100 \%$ and $98.68 \%$ respectively.

Overall diagnostic accuracy of any test implies an overall proportion of correct diagnosis made by that procedure. In our study the diagnostic accuracy of aspiration cytology is calculated as 98.93\%.Several other studies also obtained similar results. Khemka et al. ${ }^{9}$ reported it as $100 \%$, Muddegowda et al. ${ }^{20}$ as $97 \%$, Bhukari et al. ${ }^{26}$ as $98 \%$ and Panjvani et al. ${ }^{32}$ as $98.9 \%$.

In developing countries several factors like financial constraints, scarce resources put the patients at a disadvantage because of the high cost of sophisticated diagnostic methods, and in such countries, FNAC can be used as a routine diagnostic method because of its low cost. ${ }^{33}$

\section{Conclusion}

Fine needle aspiration cytology is an easy, simple, patient friendly and inexpensive procedure for primary categorization of palpable breast lumps into benign and malignant categories, but as per our observations may not be good enough for sub-categorisation of same. However, some false negative results may be invariably present, may be due to aspiration failure. Benign breast lumps far outnumber the malignant ones. Fibroadenoma and infiltrating duct carcinoma comprise majority of benign and malignant lesions respectively. Above all there is very high degree of correlation between FNAC and histopathological findings.

Thus without any hesitation we conclude FNAC to be a very important preliminary diagnostic tool in palpable breast lumps.

\section{Refrences}

1. Rahman MZ, Sikder AM, Nabi SR. Diagnosis of breast lump by fine needle aspiration cytology and mammography. Mymensingh Med J. 2011 Oct;20(4):658-664.

2. Chopra R. The Indian scene. J ClinOncol. 2001 Sep 15;19(18 Suppl):106S-111S.

3. Sankaye SB, Dongre SD. Cytological study of palpable breast lumps presenting in an Indian rural setup. Indian J Med PaediatrOncol. 2014;35(2):159-164.

4. Damjanov I., Linder J.: Anderson Pathology. $10^{\text {th }}$ edition. Vol.2, New York, Toronto, Tokyo: Mosby; 1999.

5. Pruthi, S. "Detection and Evaluation of a Palpable Breast Mass." Mayo Clinic Proceedings. Mayo Clinic 76, no. 6 (June 2001): 641-647; quiz 647-648. doi:10.4065/76.6.641.

6. Jennifer. A. Young (Ed.). Fine needle aspiration cytopathology. Blackwell Scientific Publications, Oxford 1993. No. of pages: 355.

7. H, Aiyer, Jain M, Thomas S, and Logani K. "Diagnostic Stromal Histomorphology in Fibroepithelial Breast Lesions : a Fresh Perspective." Indian Journal of Pathology and Microbiology 43, no. 1 (January 1, 2000): 5.

8. ABMZ Sadik, MM Hasan, HEZA Haque, FU Ahmed, MZ Kabir. Different Types of Breast Lump in Relation to Different Age Groups. Faridpur Med. Coll. J. 2013;8(2):56-58.

9. Khemka, N. Chakrabarti, S. Shah, V. Patel. Palpable Breast Lumps: FineNeedle Aspiration Cytology Versus Histopathology: a Correlation of Diagnostic Accuracy. The Internet Journal of Surgery 18, no. 1 (2008).

10. Pandit A.A., Mayekar K.S., Candes F.P.: Fine needle aspiration cytology of breast tumor. Indian J. of cancer 1988; 25: 136-143. 
11. Kharkwal S, Sameer null, Mukherjee A. Triple test in carcinoma breast. J ClinDiagn Res. 2014 Oct;8(10):NC09-11.

12. Tavassoli FA, Devilee P, Lyon,: WHO histological classification of tumours, pathology and genetics of tumors of The Breast and female genital organs. WHO 2005

13. Malik R, Bharadwaj VK.: Breast lesions in young females- a 20 year study for significance of early recognition. Indian Journal Pathology and Microbiology 2003; 46(4): 559-562.

14. Khanna S, Aryya NC, Khanna NN: Spectrum of benign breast diseaseA retrospective review of 22 years. Indian Journal of Surgery 1988; May-June: 169-175.

15. Langmuir V.K., Craner S.F., Hood E.M.: Fine needle aspiraton cytology in the management of palpable benign and malignant breast diseases. Correlation with clinical and mammographic findings. ActaCytol 1989; 33: 93.

16. Kumar V, Abbas AK, Fausto N, Aster JA. : Robbins and Cotran Pathologic Basis of Disease. 8th edition. New Delhi; W.B. Saunders Co., 2010

17. Mendoza, Paulo, Maribel Lacambra, Puay-Hoon Tan, and Gary M. Tse."Fine Needle Aspiration Cytology of the Breast: The Nonmalignant Categories." Pathology Research International 2011 (May 19, 2011).

18. Hanif A, Mushtaq M, Malik K, Khan A. Tuberculosis of breast. Journal Surgery Pakistan 2002;7:26-28.

19. Guray M, Sahin AA.: Benign breast Diseases: Classification, Diagnosis, and Management. The Oncologist 2006;11:435-449.

20. Muddegowda, Prakash H, Jyothi B Lingegowda, RamkumarKurpad, PG Konapur, AS Shivarudrappa, and PM Subramaniam. "The Value of Systematic Pattern Analysis in FNAC of Breast Lesions: 225 Cases with Cytohistological Correlation." Journal of Cytology / Indian Academy of Cytologists 28, no. 1 (2011): 13-19.

21. Sandhu D, Sandhu S, Karwasra R, Marwah S. Profile of breast cancer patients at a tertiary care hospital in north India. Indian Journal of Cancer. 2010;47(1):16.

22. Feichter, George E., Felix Haberthür, Susan Gobat, and Peter Dalquen. "Breast cytology." Actacytologica 41, no. 2 (1997): 327-332.
23. Patel J Janmejay et at : Fine needle aspiration cytology of breast masses : an evaluation of its accuracy and reasons for diagnostic failure. Annuals of the Royal College of Surgeons of England 1987; 69: 156-159.

24. Ellis I O, Humphreys S, Michell M, Pinder SE,Wells C A. : Non-operative Diagnosis Subgroup of the National Coordinating Group for Breast Screening Pathology NHS Cancer Screening Programmes Publication No 50. 2001.

25. Kline T.S., Neal H.S.: Needle aspiration cytology, a critical appraisal Eight years and 3267 specimens later, JAMA 1978; 239:36-39.

26. Bukhari B.M. \&Akhtar Z.M. :Comparision of Accurcy of diagnostic modalities for Evaluation of Breast Cancer. Diagnostic Cytopathology 2009:37:6:416-424.

27. Ariga R, Bloom K, Reddy VB, Kluskens L, Francescatti D, Dowlat K, et al. Fine-needle aspiration of clinically suspicious palpable breast masses with histopathologic correlation. Am J Surg. 2002 Nov;184(5):410-413.

28. Rosen P., Hajdu S.I., Robbins G., Foote F.W. : Diagnosis of carcinoma of the breast by aspiration biopsy. Surg. Gynecol and Obstet. 1972; 134: 837.

29. Medina-Franco H, Abarca-Pérez L, Cortés-González R, Soto-Germes $\mathrm{S}$, Ulloa JA, Uribe N. [Fine needle aspiration biopsy of breast lesions: institutional experience]. Rev Invest Clin. 2005 Jun;57(3):394-398.

30. Kochhar AK, Jindal U, Singh K. Spectrum of cytological findings in fine needle aspiration cytology of breast lumps with histopathology correlation: experience in a tertiary care rural hospital in India. Asian Pac J Cancer Prev. 2013;14(12):7257-7260.

31. Chaiwun B, Settakorn J, Ya-In C, Wisedmongkol W, Rangdaeng S, Thorner P. Effectiveness of fine-needle aspiration cytology of breast: analysis of 2,375 cases from northern Thailand. DiagnCytopathol. 2002 Mar;26(3):201-205.

32. Panjvani SI, Parikh BJ, Parikh SB, Chaudhari BR, Patel KK, Gupta GS, et al. Utility of Fine Needle Aspiration Cytology in the Evaluation of Breast Lesions. J ClinDiagn Res. 2013 Dec;7(12):2777-2779.

33. Zagorianakou P, Fiaccavento S, Zagorianakou N, Makrydimas G, Stefanou D, Agnantis NJ. FNAC: its role, limitations and perspective in the preoperative diagnosis of breast cancer. Eur J GynaecolOncol. 2005;26(2):143-149. 